\title{
Characteristics of Asphalt Binder and Mixture Modified With Waste Polypropylene
}

\author{
Wissam N. Abdulkhabeer ${ }^{\mathrm{a}}$, Mohammed Y. Fattah $\mathbb{D}^{\mathrm{b}^{*}}$, Miami M. Hilal $\mathbb{D}^{\mathrm{c}}$ \\ ${ }^{\text {a }}$ Directorate of Roads and Bridges, Karbala, Iraq, \\ ${ }^{\text {b,c }}$ Civil Engineering Department, University of Technology, Baghdad, Iraq. \\ *Corresponding author Email: 40011@,uotechnology.edu.iq
}

\section{H I G H L I G H T S}

- This paper investigates the probability of using Waste Polypropylene (WPP) as modifier.

- It is aimed to enhance the properties of asphalt binder and mixture.

- Two types of asphalt binder (40/50) and (60/70) were used.

- Three percentages of WPP $(1 \%, 3 \%$, and $5 \%)$ were added to $(60 / 70)$ asphalt binder/mixture,

- The outcomes indicated that $3 \%$ of WPP was optimum percentage that gave best results.

\section{A R T I C L E I N F O}

Handling editor: Wasan I. Khalil

\section{Keywords:}

Asphalt Binder

Asphalt Mixture

Marshall Stability

Marshall Flow

Modified Binder

Modified Mixture

Waste Polypropylene

\section{Introduction}

Road pavements under intensive environmental effects cannot always meet the desirable quality requirements. For instance, the impact of temperature differences between summer and winter, the load deformation and so on. This results in the fact that pavement service life is decreased[1]. Road pavements have also thermal susceptibilities and often experience thermal cracking in cold weather and creep and distortion in high temperature regions[2]. Moreover, traffic road volume raises and requires a coinciding increase in load bearing capacities of pavements and their service life span. Such factors illustrate the need for developing bitumen with enhanced characteristics compared to that of conventional asphalt binder[3].

Investigators are constantly induced to investigate the probability of utilizing different kinds of waste materials as bitumen modifiers in hot mix asphalt industry (HMA). The fact that the conventional bitumen is relatively expensive besides the massive regulations of the environmental authorities formed some serious motivations for them[4].

The design of improved asphalt mix is achieved using three major variables; weight of scrap tires replaced by coarse base aggregate, particles size of scrap tires, and finally the weight of binder used (bitumen). The improved asphalt mix (IAM) requires a balance between rut resistance and durability to resist cracking and moisture damage (stripping). Accordingly, several factors that influence rut resistance and durability are considered during the design process [5]. 
It has been manifested that the performance of bituminous mixtures implemented in the wearing course of road pavements is possible to be enhanced with the aid of different kinds of additives to bitumen like crumb rubber, polymers, and rubber latex, etc.[6].The most used modifiers or additives in HMA industry are polymers, mostly virgin elastomer, and plasterer, but more recently other polymers from plastic wastes have also been investigated. The plastic wastes can improve the properties of asphalt binder and, consequently, the performance and durability of the asphalt mixtures and they present environmental and economic advantages. On this basis, asphalt can be partially replaced by waste plastics [7].

Every day, several types of materials that are either entirely or partly manufactured of plastics are utilized and lastly end up in garbage. The improper disposal of these plastic wastes has become a serious issue particularly in urban areas in terms of its misuse, clogging of drains, its dumping in the dustbin, and aesthetic issues, etc. Depending on plastics quality, they may take anywhere from days to many years to molder in landfills, however, they never decompose entirely in a way that may be utilized by nature. Therefore, plastics are considered to be from the worst waste materials when it comes to environmental contamination and it is required that these wastes must be recycled and not disposed in landfills[6,8].

The objective of this study is to investigate the possibility of utilizing waste polypropylene as asphalt cement modifier to enhance asphalt properties as well as eliminate these waste materials.

\section{Methodology}

The laboratory work of this study consists of modifying the 60/70 asphalt binder with WPP and comparing the results of modified binder/mixture samples with the original 60/70 binder/mixture and the base 40/50 binder/mixture besides evaluating the results with the specifications of State Corporations of Roads and Bridges in Iraq SCRB (SCRB/ R9-2003) [9]. Figure 1 shows the work methodology implemented in this study.

\section{Materials USED}

\subsection{Asphalt Binder}

Asphalt cement with penetration grade of 60/70 was used for modification process with WPP, while 40/50 asphalt binder was used for comparison purposes since 40/50 binder is the mostly implemented asphalt in the construction of flexible pavements in Iraq. Both theses binders were obtained from Al-

Dora refinery in Baghdad and their properties are presented in Table 1.

\subsection{Aggregate and Filler}

The local aggregate implemented in laboratory work is crushed quartz obtained from Al-Nibaie Quarry, which is widely used for bituminous mixtures in Iraq, while the Portland cement, which was used as mineral filler, was obtained from Al-Kufa factory, Iraq. One aggregate gradation was used in this study as shown in Figure 2 for implementation in wearing course which has nominal maximum aggregate size of $1 / 2$ ". The gradations are presented in Table 2 .

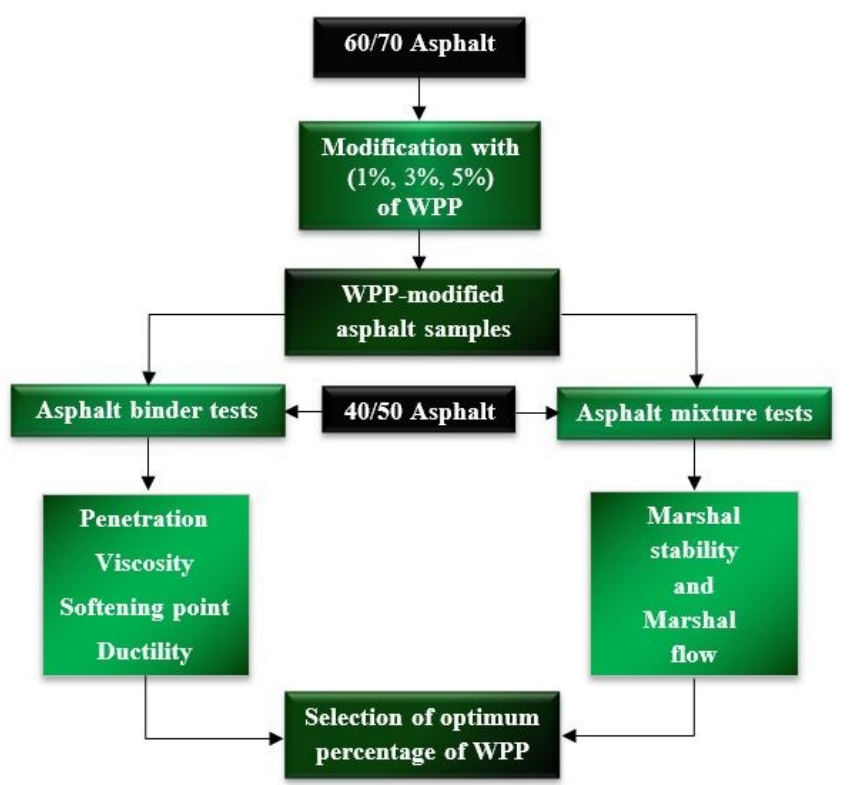

Figure 1: Work methodology of the study

Table 1: Properties of $40 / 50$ and $60 / 70$ asphalt binders

\begin{tabular}{ccccc}
\hline Property & Results of 40/50 & SCRB specification of & Results of 60/70 & SCRB specification \\
Asphalt & $40 / 50$ asphalt & Asphalt & of 60/70 asphalt \\
\hline
\end{tabular}




\begin{tabular}{|c|c|c|c|c|}
\hline Penetration & 47 & $40-50$ & 66 & 66 \\
\hline Ductility $(\mathrm{cm})$ & 146 & $>100$ & $>150$ & $>100$ \\
\hline Kinematic viscosity (cSt) & 420 & Min. 400 & 387 & Min. 300 \\
\hline Softening point $\left({ }^{\circ} \mathrm{C}\right)$ & 51 & $\ldots$ & 47 & $\cdots$ \\
\hline Flash point $\left({ }^{\circ} \mathrm{C}\right)$ & 279 & Min. 232 & 267 & Min. 232 \\
\hline Specific gravity & 1.051 & $\ldots$ & 1.46 & $\ldots$ \\
\hline
\end{tabular}

\subsection{Waste Polypropylene (WPP)}

The waste polypropylene utilized in this study was obtained from a waste plastic recycling factory in Bab Al-Sham, Baghdad in the form of small pieces. This waste plastic was washed and further grinded into powder and sieved on \#50 sieve. Figure 3 illustrates the utilized waste Polypropylene and Table 3 presents its properties.

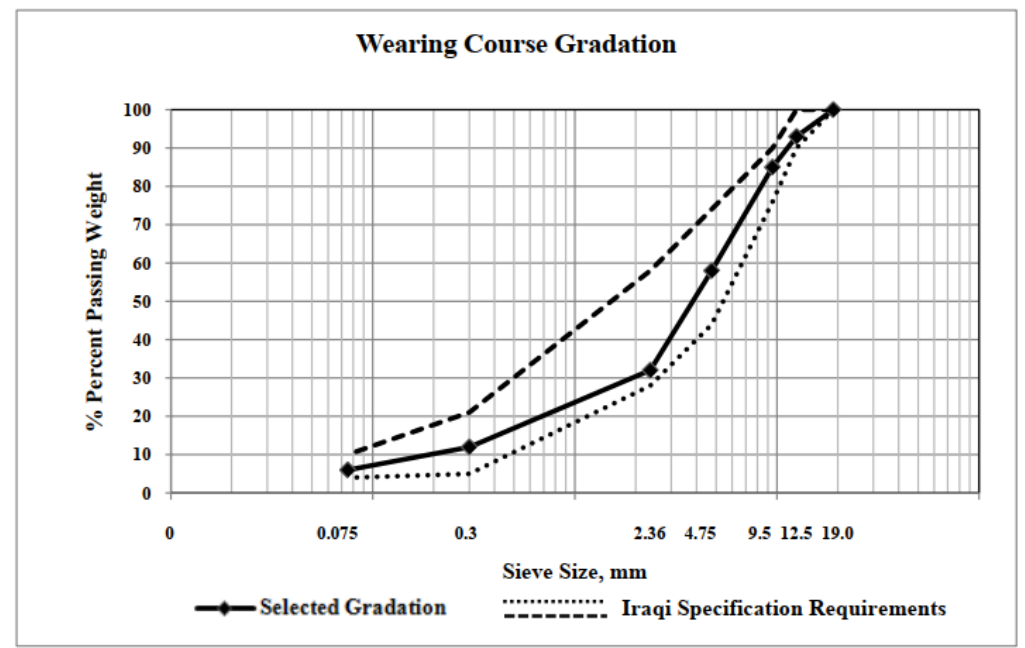

Figure 2: Asphalt mixture gradation with Iraqi specification limits.

Table 2: Selected gradations for asphalt concrete mixtures (wearing course).

\begin{tabular}{ccc}
\hline $\boldsymbol{m} \boldsymbol{m}$ & Sieve size & Percent passing (\%) \\
\hline 37.5 & $11 / 2 ”$ & $\ldots$ \\
25 & $1 ”$ & $\ldots$ \\
19 & $3 / 4 ”$ & 100 \\
12.5 & $1 / 2{ }^{\prime \prime}$ & 93 \\
9.5 & $3 / 8^{\prime \prime}$ & 85 \\
4.75 & No.4 & 58 \\
2.36 & No.8 & 32 \\
$300 \mu \mathrm{m}$ & No. 50 & 12 \\
$75 \mu \mathrm{m}$ & No. 200 & 6 \\
\hline
\end{tabular}

Table 3: Properties of the used waste polypropylene

\begin{tabular}{cc}
\hline Property & WPP \\
\hline Melting temperature $\left({ }^{\circ} \mathrm{C}\right) *$ & 160 \\
$\begin{array}{c}\text { Specific gravity } * \\
\text { Maximum particle size after grinding and } \\
\text { sieving (mm) }\end{array}$ & 0.91 \\
\hline
\end{tabular}

* The property was obtained from the plastic factory from which this WPP was taken. 


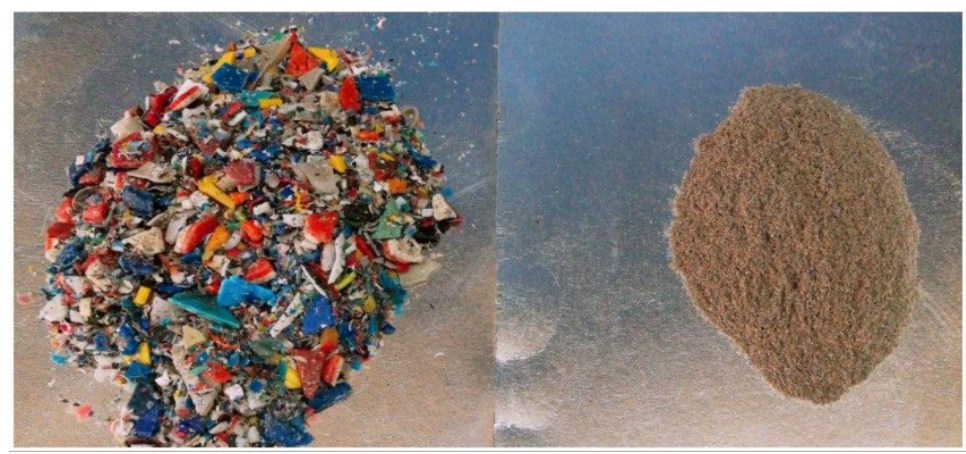

Figure 3: Waste Polypropylene

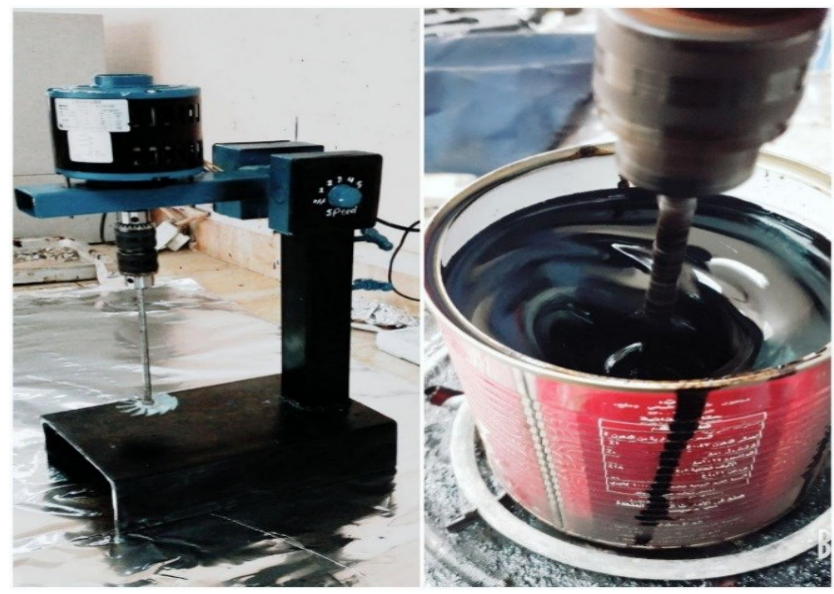

Figure 4: Mixing process of WPP with asphalt binder

\subsection{Sample's preparation}

The preparation of WPP-modified binders consists of adding three percentages (1\%, 3\% and 5\%) of WPP powder to the 60/70 asphalt binder as suggested by Habib et al.(2011) [10]. WPP and asphalt binder were blended using laboratory mixer for (1) hr. at (1300) rpm to gain a homogeneous mixture as shown in Figure 4. The addition of WPP was during the bitumen being heated at temperature of $(165 \pm 5){ }^{\circ} \mathrm{C}$. WPP-modified asphalt mixtures were prepared by mixing the obtained WPP-modified binders along with the aggregate and filler at $(150)^{\circ} \mathrm{C}$ (wet process).

\subsection{Tests}

The following bitumen tests were conducted on the 40/50 and 60/70 asphalt cements and all the modified asphalt specimens: penetration, softening point, ductility, and kinematic viscosity according to ASTM D5, D36, D113, D2170, D 92, D 70 and D 1754 respectively [11-14]to investigate the effects of WPP additive on physical properties of asphalt binder. Furthermore, asphalt mixtures with 40/50 binder, 60/70 binder, and WPP-modified binders were tested in Marshal stability and flow tests according to ASTM D6927 [14].

\section{Results and discussion}

\subsection{Asphalt binder results}

The results of the physical tests; penetration, softening point, viscosity, and ductility, performed on base 40/50 asphalt, 60/70 asphalt and WPP-modified asphalt binders are shown in Figure 5.

It is clear from this figure that the penetration grade of 60/70 asphalt binder decreased with the addition of WPP until it reached 30/40 grade with 5\% of WPP additive. Compared to base 40/50 asphalt binder, 3\% of WPP was the required percentage to gain the same $40 / 50$ penetration grade. The decrease in penetration is because the hardness of bitumen increased with the addition of WPP, where this reduction can be attributed to a change in phase in the binder upon the addition of WPP which resulted in increased internal resistance.

As for softening point, the addition of WPP has increased the softening point of the resulted binders which results in asphalt binders with higher resistance to temperature compared to the original $60 / 70$ binder. It can also be noted that $3 \%$ of WPP, which has 40/50 penetration grade, has higher softening point compared with the base 40/50 asphalt binder. The high resistance of WPP to elevated temperatures, compared to bitumen, is the reason behind the increase in softening point of the resulted binders.

Furthermore, Figure 5 also presents kinematic viscosity test results at $135{ }^{\circ} \mathrm{C}$. It can be noted that viscosity values of asphalt binder increased with increasing the dosage of WPP. Also, 3\% of WPP that resulted in 40/50 penetration grade, has higher viscosity values in comparison with the base 40/50 asphalt. The increase in asphalt viscosity is due to the hardness 
effect of WPP on asphalt binder which is supported by the decrease in penetration values. The increase in viscosity values would help to improve the resistance to permanent deformations at elevated temperatures thereby increasing the service life of the pavement. Asphalt is a viscoelastic material; temperature has an important effect on its stiffness properties. The fatigue damage or cracking of an asphalt pavement caused by traffic loads is influenced by the stiffness properties of the mix. Fattah et al. (2014) [16] found that the initial stiffness is affected by temperature variation.

Moreover, it is also clear from Figure 5 that asphalt ductility values decrease as WPP was added, where the ductility of near 60/70 asphalt was higher than $150 \mathrm{~cm}$ and decreased to $96 \mathrm{~cm}$ with $5 \%$ of WPP addition which is below specification limits. However, $1 \%$ and $3 \%$ of WPP addition has resulted in ductility values within specification limits (above $100 \mathrm{~cm})$. The decrease in ductility values is the result of the hardness effect of WPP on asphalt binder, which means that the modified binders tend to show more brittle behavior at low temperatures compared to original $60 / 70$ asphalt binder. Nonetheless, $3 \%$ of WPP has resulted in ductility value close to that of base 40/50 asphalt binder.

\subsection{Asphalt mixture results}

The results of Marshall test (stability, flow, and stiffness) on original and modified asphalt mixtures are shown in Figure 6. It can be seen from this figure that the stability values of 60/70 asphalt mixture is (6.5) which is lower than that of $40 / 50$ asphalt mixture and it is also below SCRB specification limits for wearing course. With the addition of WPP, stability values of modified mixtures increased where $3 \%$ and $5 \%$ of WPP resulted in stability values higher than that of base $40 / 50$ asphalt mixture and exceeded the minimum required value for wearing course according to SCRB specifications that marked in Figure 6. The increase in stability values with the addition of WPP is supported by the increase in viscosity values of WPP-modified binders.

Conversely, the values of asphalt mixtures' flow have decreased with the addition of WPP where the flow value of original $60 / 70$ asphalt mixture was (5) which is higher than specification limits and decreased to (3.5) and (2.5) with $1 \%$ and $3 \%$ of WPP addition respectively to be within specification limits. The reduction in flow values of WPP-modified mixtures is also supported by the decrease in ductility values of WPP-modified binders. Like the case for stability, stiffness values of modified mixtures, which resulted from dividing stability overflow, were also increased with the addition of WPP.

It can also be seen from Figure 6 that $3 \%$ addition of WPP is the optimum percentage for asphalt modification since it gave the best results in comparison with the base 40/50 asphalt mixture and SCRB specifications.

The results of Khalaf et al. (2020) [17] showed that the SBS polymer asphalt mixture gave better moisture sensitivity and better fracture resistance according to the study. It was noted that indirect tensile strength ratio (TSR) increases by $93.1 \%$ and the rut depth decreases by $32.5 \%$ when adding $3 \%$ SBS polymer to SMA.

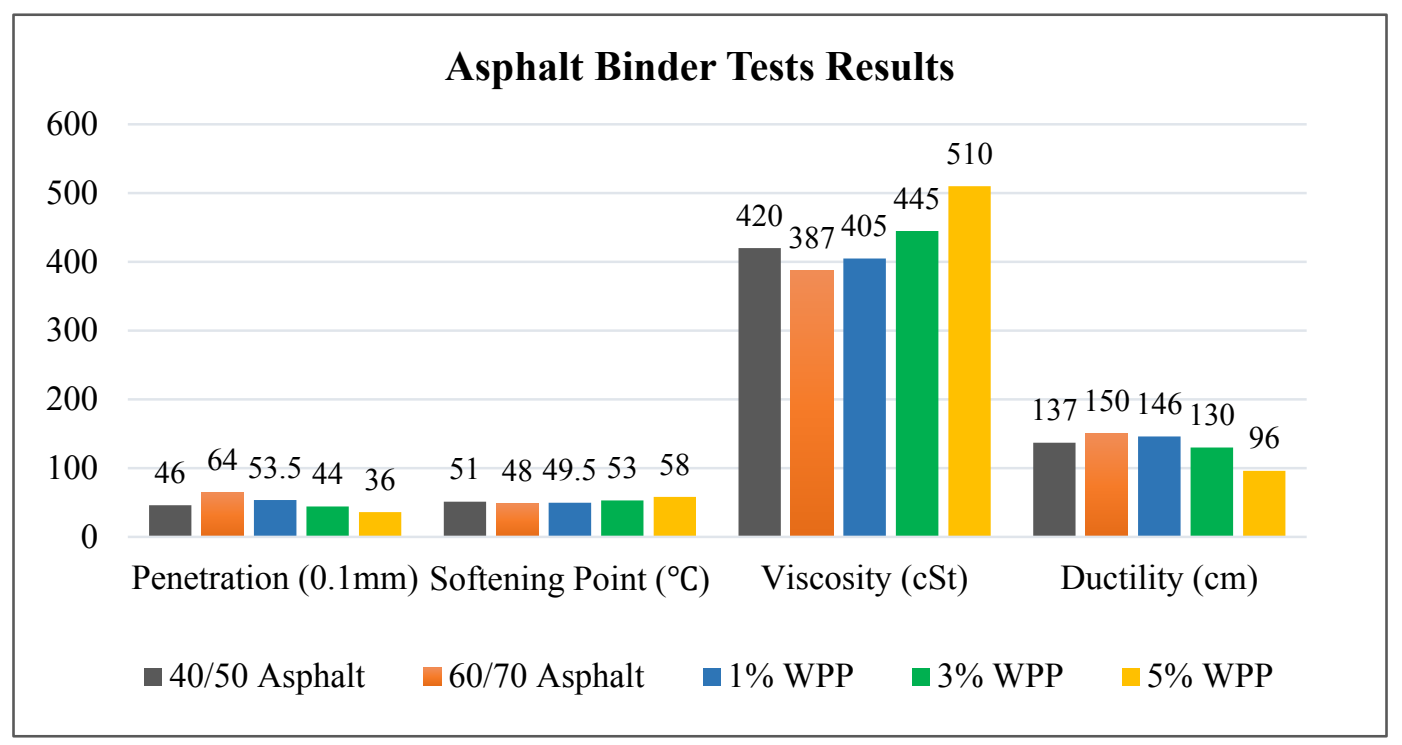

Figure 5: Tests results of original and modified asphalt binders. 


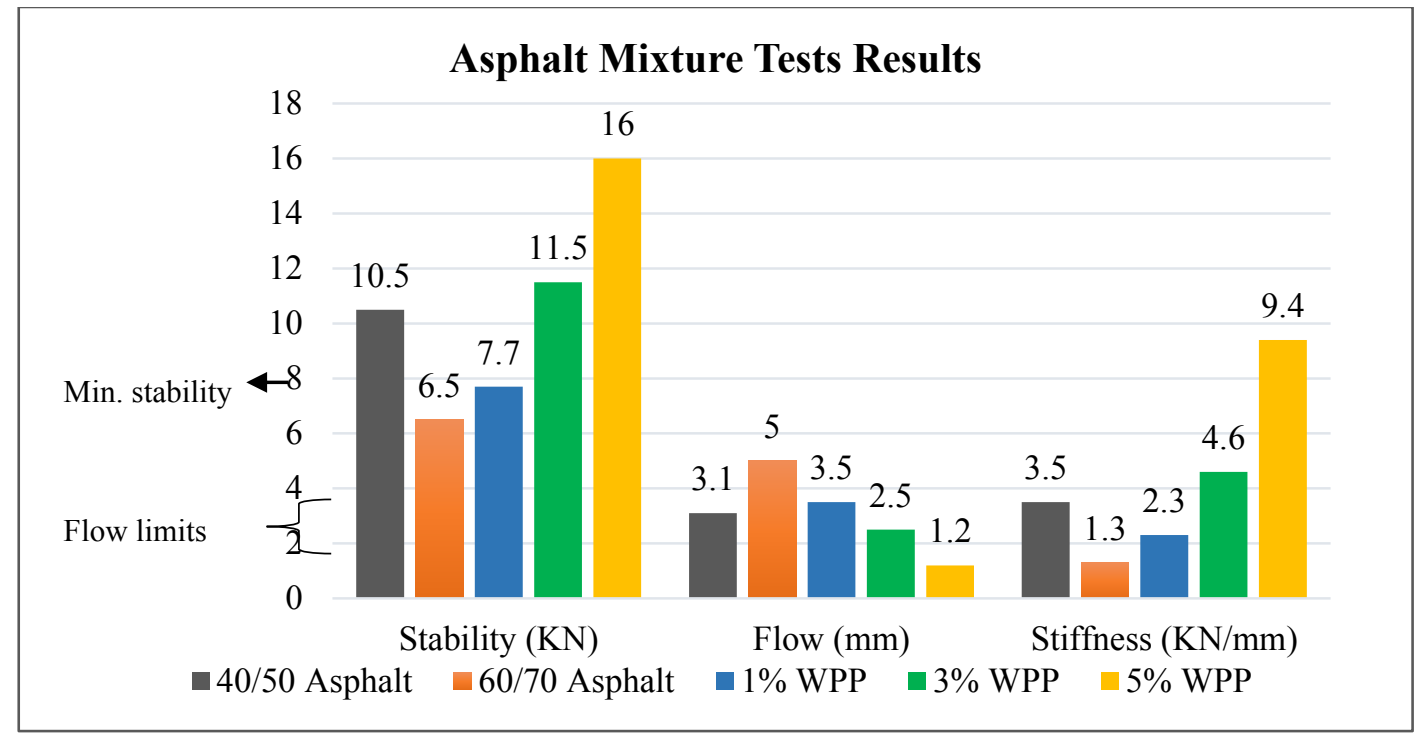

Figure 6: Tests results of original and modified asphalt mixtures.

\section{Conclusions}

1) WPP has significant effect on modifying the soft (high grades) asphalt binders due to the decrease in penetration values (increase in the consistency) with the addition of WPP.

2) The addition of WPP to the asphalt binder resulted in modified binders with higher viscosity (higher resistance to permanent deformation) but with lower ductility (lower thermal crack resistance).

3) WPP-modified binders have higher resistance to elevated temperature due to the higher softening point values.

4) The stability of asphalt mixture increases with the addition of WPP which indicates higher resistance to permanent deformation.

5) The addition of WPP results in modified asphalt mixtures with better flow values compared to the original mixture.

6) $3 \%$ of WPP is the optimum percentage to be added to $60 / 70$ asphalt which resulted in better outcomes for asphalt binder/mixture compared to the original binder/mixture and within specification limits.

7) Finally, it can be concluded that the properties of asphalt binder/mixture can be enhanced with the addition of WPP, especially for high temperature regions. Also, it can be reported that the recycling of WPP in HMA industry is feasible which would also decrease the negative environmental effects.

8) For future works, it is suggested to investigate the influence of other types of waste materials like; waste glass, waste wood ash and other types of plastic wastes on the properties of asphalt binder/mixture besides implementing a combination of two or more waste materials as additives in modification process.

\section{Acknowledgments}

The authors would like to thank the University of Technology and the Directorate of Roads and Bridges of Karbala Province in Iraq for their assistance.

\section{Author Contribution}

All authors contributed equally to this work.

\section{Funding}

This research received no specific grant from any funding agency in the public, commercial, or not-for-profit sectors.

\section{Data Availability Statement}

The data that support the findings of this study are available on request from the corresponding author.

\section{Conflicts of Interest}

The authors declare that there is no conflict of interest.

\section{References}

[1] K. E., Syrmanova, D., Botashev, M., Tleuov, A., Suleimenova, A., Eshankulov and Z. B.Kaldybekova. "Research of oil road bitumen modification with low densitypolyethylene."Oriental jornal of chemistry 33(1): 470-477, 2017. 
[2] R., Maharaj, R. and C. Maharaj "Physical properties of low-density polyethylene,polyvinylchloride and used engine oil modified asphalt." Progress in Rubber,Plastics andRecycling Technology 31(3): 173-188, 2015.

[3] S. L., Fernandes, H., Costa Silva and J. Oliveira. "Effect of incorporatingdifferent waste materials in bitumen." Ciência\&Tecnologia dos Materiais 29(1):204-209, 2017.

[4] A. A., Al-Omari, T. S. Khedaywi and M. A. Khasawneh. "Laboratorycharacterization ofasphalt binders modified with waste vegetable oil usingSuperPave specifications." International Journal of Pavement Research andTechnology 11(1): 68$76,2018$.

[5] F. O.Abass, M. O., Abass and R. O., Abass, "Optimization of Asphalt Mix Improved by the Addition of Scrap Tires", Engineering and Technology Journal, University of Technology, Iraq, Vol. 27, No. 12, pp. 2425-2446, 2009.

[6] J. K. Appiah, V. N. Berko-Boateng and T. A. Tagbor. "Use of waste plasticmaterials for road construction in ghana." Case Studies in Construction Materials 6:1-7, 2017.

[7] S. R., Fernandes, L. Costa, H. M. R. D. D., Silva, and J., Oliveira. Utilization of waste materials to improve asphalt mixtures performance. In 6th International Conference on Mechanics and Materials in Design (pp. 2047-2052). INEGIFEUP, 2015.

[8] S. N., Nemade, and P. V. Thorat. "Utilization of polymer waste for modificationof bitumen in road construction." Sci. Revs. Chem. Commun3(4): 198-213, 2013.

[9] SCRB/R9 2003. General Specification for Roads and Bridges, Section R/9, Hot-Mix Asphalt Concrete Pavement, Revised Edition. State Corporation of Roads and Bridges, Ministry of Housing and Construction, Republic of Iraq.

[10] N. Z., Habib, I. M.,Kamaruddin, M., Napiah, and I. M., Tan. "Effect of Mixing Process on Polypropylene Modified Bituminous Concrete Mix Properties", International Journal of Civil and Environmental Engineering Vol:5, No:10, 2011.

[11] ASTM D5-2006, Standard Test Method for Penetration of Bituminous Materials,ASTM International, West Conshohocken.

[12] ASTM D36-95, Standard Test Method for Softening Point of Bituminous Materials(Ring-and-Ball Apparatus), ASTM International, West Conshohocken.

[13] ASTM D113-99, Standard Test Method for Ductility of Bituminous Materials, ASTMInternational, West Conshohocken.

[14] ASTM D2170-10, Standard Test Method for Kinematic Viscosity of BituminousMaterials, ASTM International, West Conshohocken.

[15] ASTM D6927-15, Standard Test Method for Marshall Stability and Flow of Asphalt Mixtures, ASTM International, West Conshohocken.

[16] M. Y., Fattah, K. H. I., Al Helo, Z. I., Qasim, "Fatigue Cracking Performance of Local Superpave Asphalt Concrete Mixtures", Engineering and Technology Journal, University of Technology, Iraq, Vol. 32, Part (A), No. 12, pp. 2904-2920, 2014.

[17] D. A. Khalaf, Z. I., Qasim, K. H., Al Helo., "Effect of Modified Asphalt Cement of the Performance of Stone Matrix Mixtures", Engineering and Technology Journal, University of Technology, Iraq, Vol. 38, Part (A), No. 5, pp. 789-800, 2020. 